\title{
Compartmentalized signaling by GPI-anchored ephrin-A5 requires the Fyn tyrosine kinase to regulate cellular adhesion
}

\author{
Alice Davy, ${ }^{1,2}$ Nicholas W. Gale, ${ }^{3}$ Elizabeth W. Murray, ${ }^{1}$ Richard A. Klinghoffer, ${ }^{4}$ Philippe Soriano, ${ }^{4}$ \\ Claude Feuerstein, ${ }^{2}$ and Stephen M. Robbins ${ }^{1,5}$ \\ ${ }^{1}$ Departments of Oncology and Biochemistry and Molecular Biology, University of Calgary, Calgary, Alberta T2N-4N1 \\ Canada; ${ }^{2}$ Laboratorie de Physiologie Section Neurophysiologie, University Joseph Fourier, Pav Neurology, Institut National \\ de la Santé et de la Recherche Médicale (INSERM) U318, Centre Hospitalier Universitaire de Grenoble, BP217, F-38043 \\ Grenoble CEDEX 9, France; ${ }^{3}$ Regeneron Pharmaceuticals, Inc., Tarrytown, New York 10591 USA; ${ }^{4}$ Fred Hutchinson Cancer \\ Research Center, Seattle, Washington 98109-1024 USA
}

Eph receptor tyrosine kinases and their corresponding surface-bound ligands, the ephrins, provide cues to the migration of cells and growth cones during embryonic development. Here we show that ephrin-A5, which is attached to the outer leaflet of the plasma membrane by a glycosyl-phosphatidylinositol-anchor, induces compartmentalized signaling within a caveolae-like membrane microdomain when bound to the extracellular domain of its cognate Eph receptor. The physiological response induced by this signaling event is concomitant with a change in the cellular architecture and adhesion of the ephrin-A5-expressing cells and requires the activity of the Fyn protein tyrosine kinase. This study stresses the relevance of bidirectional signaling involving the ephrins and Eph receptors during brain development.

[Key Words: GPI anchor; ephrin-A5; cell adhesion; signaling; Fyn tyrosine kinase]

Received August 17, 1999; revised version accepted October 13, 1999.

Ephrins are surface-bound ligands for the large family of Eph receptor tyrosine kinases (RTKs) that have key roles during developmental processes such as the control of angiogenesis, axonal guidance, and axonal fasciculation (Drescher et al. 1997; Frisén and Barbacid 1997; Gale and Yancopoulos 1997; Yancopoulos et al. 1998). In addition, their complementary and mutually exclusive expression patterns suggests an involvement in the formation of spatial boundaries and tissue morphogenesis during embryogenesis (Friedman and O'Leary 1996; Gale et al. 1996). The ephrins are divided into two major classes based on their differential affinity for distinct classes of Eph receptors (Gale et al. 1996). Interestingly, the two classes of ephrins are structurally diverse-ephrins-A are tethered to the plasma membrane by virtue of a glycosylphosphatidylinositol (GPI) anchor, whereas ephrins-B are transmembrane proteins.

Many of the ephrins and Eph receptors have been shown to be expressed in the developing nervous system where they participate in the topographic patterning of neuronal connections (for review, see Drescher et al. 1997). The analysis of mice lacking the gene encoding ephrin-A5 provides evidence for the importance of this

${ }^{5}$ Corresponding author.

E-MAIL srobbins@ucalgary.ca; FAX 403-283-8727. ligand for the proper guidance and topographic organization of retinal axons in the midbrain (Frisén et al. 1998). In vitro models also support a role for these molecules in axon fasciculation and guidance (Drescher et al. 1995; Winslow et al. 1995; Caras 1997; Meima et al. 1997; Gao et al. 1998). Ephrins have been attributed the unique function of being repulsive cues for receptor-bearing axons by promoting the collapse of the actin cytoskeleton within the growth cone, thereby controling axonal pathfinding (Gale and Yancopoulos 1997).

With the recent discovery that the transmembrane ligands (ephrin-B) for the Eph receptors could themselves induce a cellular signaling response of their own (Henkemeyer et al. 1996; Holland et al. 1996; Brückner et al. 1997), we sought to examine whether the GPI-anchored ligands, particularly ephrin-A5, were also competent to communicate an intracellular signal and what phenotypic effect this may have on the ligand-expressing cell. The notion that GPI-anchored ephrins that do not span the plasma membrane can signal upon interaction with their cognate Eph receptor is supported by previous observations where other GPI-anchored proteins, mainly present on hematopoietic cells, activate cellular signaling responses upon cross-linking or binding to their natural ligands (Brown 1993).

It is now known that the plasma membrane contains 
specific microdomains that can be purified from a wide variety of cells and tissues (Simons and Ikonen 1997; Anderson 1998). They are characterized by their enrichment in glycosphingolipids and cholesterol and by their unique protein composition (Simons and Ikonen 1997; Anderson 1998). On the extracellular face of the plasma membrane, GPI-anchored proteins accumulate in these detergent-insoluble glycolipid-enriched complexes (DIGs) (Brown and Rose 1992; Anderson 1998), whereas proteins such as G proteins and members of the Srcfamily of protein tyrosine kinases are found associated with the inner leaflet of these lipid-rich domains (Sargiacomo et al. 1993; Shenoy-Scaria et al. 1994; Robbins et al. 1995). The localization of various signaling competent molecules has allowed one to propose that these microdomains act as sites of signal integration. DIGs represent at least two different types of microcompartments that can be distinguished by their shape and protein composition (Simons and Ikonen 1997). Caveolae are one such type of compartment, characterized by the presence of caveolin-1, a 22-kD protein known as the structural component of these small flask-shaped caves (Rothberg et al. 1992; Monier 1995). In addition to caveolin-1, there are now two additional members of this family, caveolin-2 and caveolin-3, but their role in the formation of caveolae is still unclear (Way and Parton 1995; Scherer et al. 1996; Tang et al. 1996). Although caveolae were originally thought not to be present in cells of neuronal origin, recent reports have demonstrated that caveolin-1 and caveolin-2 are expressed in the brain (Cameron et al. 1997; Ikezu et al. 1998), suggesting that they have a role in neuronal physiology.

When ectopically expressed in murine fibroblasts, ephrin-A5 is localized to caveolae-like plasma membrane microdomains. Upon interaction with its cognate receptor, ephrin-A5 is able to induce a signaling event within the microdomains, requiring the activity of the Fyn protein tyrosine kinase. The physiological consequence of such a signaling event is concomitent with alterations in the cytoskeletal architecture consistant with the regulation of the adhesive properties of the ephrin-A-expressing cells. This study stresses the essential role that caveolae-like membrane microdomains have in signal transduction, particulary during the development of the nervous system. In addition, this work provides evidence for the physiological significance of bidirectional signaling on interaction between the Eph receptors and their corresponding ephrins in controlling patterning during brain development.

\section{Results}

\section{Ephrin-A5 is compartmentalized in discrete caveolae-like membrane microdomains}

To examine the potential signaling capabilities of ephrin-A5, we have constructed murine fibroblast cell lines that ectopically express the human ephrin-A5 protein on their cell-surface. Ephrin-A5 expression in the individual clones was detected by indirect immunofluorescence using a chimeric protein composed of the extracellular ligand-binding domain of ephrin-A5 fused with the Fc fragment of human IgG (EphA5-Fc) (Davis et al. 1994). Subsequently, we confirmed expression using a monoclonal antibody specific for ephrin-A5 (clone 5G2). Whereas parental murine fibroblasts were negative for ephrin-A5 expression, the transfected cell lines were positive (Fig. 1). Two independent clones (A5.1 and A5.2) have been used throughout this study showing no differences in any of the biological assays.

As mentioned previously, GPI-linked proteins are localized within specialized microdomains known as DIGS, which in some cell types have been equated to caveolae (Anderson 1993; Harder and Simons 1997). To investigate whether ephrin-A5 was localized in similar
A
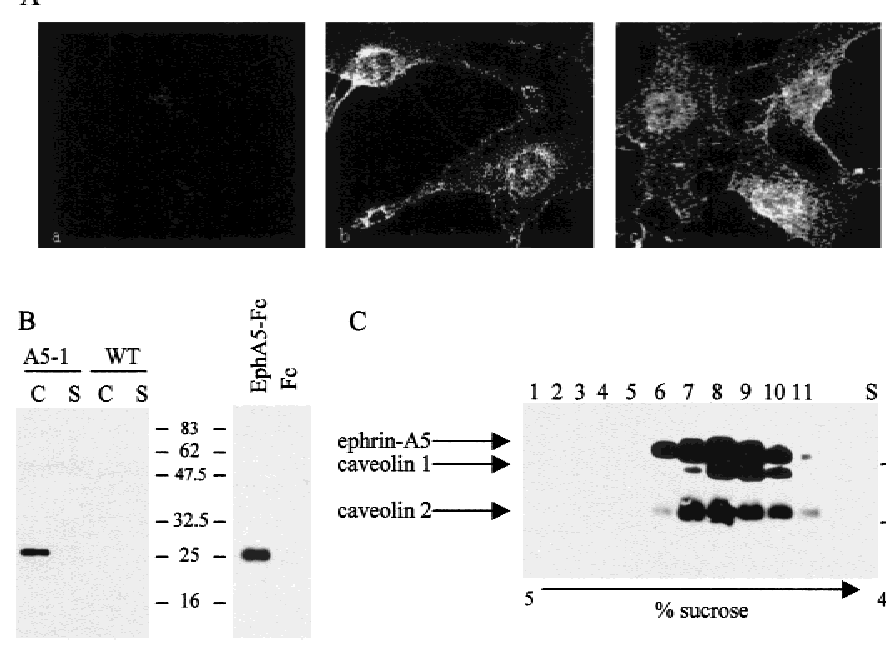

$\mathrm{C}$

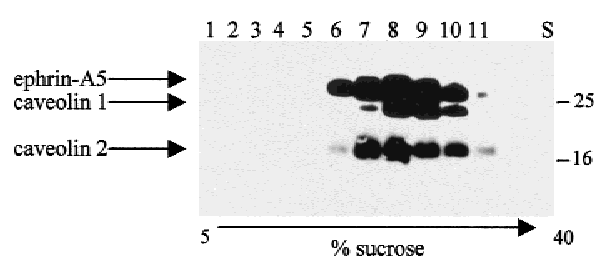

Figure 1. Ephrin-A5 is compartmentalized within discrete plasma membrane microdomains. (A) NIH-3T3 cells stably expressing human ephrin-A5 were subjected to immunofluorescence using the $\mathrm{Fc}$ fragment of human IgG as negative control $(a)$, the EphA5-Fc fusion protein $(8 \mu \mathrm{g} / \mathrm{ml})$ to detect the ephrin-A5 protein $(b)$, or caveolin-1-specific monoclonal antibody $(c)$. (B) NIH-3T3 cells ectopically expressing ephrin-A5 (A5-1) or wild type (WT) were lysed in $1 \%$ Triton $\mathrm{X}-100$, and the caveolar (C) and Triton X-100 soluble (S) fractions were collected as described previously (Robbins et al. 1995) (left). The isolated caveolae-like fraction from ephrin-A5-expressing cells was incubated with $5 \mu \mathrm{g}$ of either EphA5-Fc or Fc fusion proteins, pelleted by the addition of protein A-Sepharose and analyzed by immunoblotting (right). Both blots were probed with a monoclonal antibody to ephrin-A5 (clone 5G2). (C) The ephrin-A5-expressing fibroblasts were lysed in 1\% Triton X-100 and fractionated by linear sucrose gradients $(5 \%-40 \%)$ as above, except individual $1-\mathrm{ml}$ aliquots were collected and subjected to a Western blot analysis using caveolin-1, caveolin-2, and ephrinA5-specific antibodies as indicated. Molecular mass standards are labeled $(\mathrm{kD})$. 
microdomains, the EphA5-Fc receptor was bound to the ephrin-A5-expressing cells and detected with a fluorescently labeled secondary antibody specific for the Fc fragment of human IgG. The staining pattern obtained after binding of the EphA5-Fc receptor chimera was located at the plasma membrane with a punctate distribution throughout the cell, suggesting that ephrin-A5 is localized in discrete domains within the plasma membrane (Fig. 1A). This staining pattern was reminiscent of the pattern obtained using a specific antibody for the structural resident protein of caveolae, caveolin-1 (Rothberg et al. 1992) (Fig. 1A), suggesting that ephrin-A5 and caveolin-1 have similar compartmentalized subcellular distributions.

We have been able to confirm these results biochemically by isolating the detergent-insoluble low buoyant density (caveolae-like) fraction of cells expressing ephrin-A5 as we and others have described previously (Chang et al. 1994; Lisanti et al. 1994; Robbins et al. 1995). Through the use of a monoclonal antibody specific for ephrin-A5, a single protein was detected that associates with the caveolae-like fraction of the cells transfected with ephrin-A5 cDNA (Fig. 1B). This protein was not present in wild-type (Fig. 1B, left) or mock-transfected NIH-3T3 cells (data not shown). The presence and identity of ephrin-A5 in the caveolae-like fraction, was also verified using the EphA5-Fc chimera as an affinity reagent to precipitate the GPI-linked protein from the caveolar fraction of ephrin-A5 expressing cells (Fig. 1B, right). Stepwise fractionation of the sucrose gradients, and subsequent immunoblot analysis of the individual fractions showed that ephrin-A5, caveolin-1, and caveolin-2 copurify on these gradients, further indication that all three proteins localize in discrete membrane microdomains with similar biochemical properties (Fig. 1C). There were no detectable changes in the subcellular distribution of caveolin 1 or 2 whether ephrin-A5 was present in the fibroblasts or not (data not shown). Furthermore, the localization of ephrin-A5 within the caveolaelike fraction did not change upon binding of the EphA5Fc receptor chimera (data not shown). The results obtained by immunofluorescence staining and biochemical fractionation argue for a permanent localization of ephrin-A5 within discrete microdomains of the plasma membrane. Immunofluorescent staining for ephrin-A5 and caveolin-1, however, only partially overlap. This may suggest that the ephrin-A5 containing fraction is distinct from bona fide caveolae and therefore has been designated "caveolae-like" microdomains.

Ephrin-A5 is able to initiate a signaling event within the caveolae-like domain upon binding to its cognate receptor requiring the activity of Src-family kinases

To determine whether ephrin-A5 was competent to promote an intracellular signal when bound to its cognate Eph receptor, stimulation of the cells expressing ephrinA5 was performed by binding the soluble EphA5-Fc re- ceptors. The binding of EphA5-Fc did not induce any changes in the general tyrosine phosphorylation content of NIH-3T3 cells expressing ephrin-A5 (data not shown). When the caveolae-like fraction was analyzed, however, EphA5-Fc binding induced an increase in the phosphotyrosyl level of at least two proteins (p60 and p75-80) present in this membrane compartment (Fig. 2A). As a control for quantitation of the isolated caveolae-like domains, the blots were reprobed with a caveolin-2-specific antibody (Fig. 2). Although caveolin-2 levels remained constant, the tyrosine phosphorylation of p60 and p7580 (referred to hereafter as p80 for simplicity) increased dramatically, reaching maximal levels $15 \mathrm{~min}$ after stimulation with Eph-Fc (Fig. 2B). Fc alone was not sufficient to induce tyrosine phosphorylation in this caveolar compartment. Furthermore, when the same experiment was performed on parental or mock-transfected NIH-3T3 cells that did not contain ephrin-A5 cDNA, incubation with EphA5-Fc did not induce any change in the tyrosine phosphorylation pattern in the caveolae-like fraction of these cells (data not shown). A detailed time course demonstrated that the increased tyrosine phosphorylation levels in the caveolae-like domains of the cells induced by binding of EphA5-Fc was concomitant with the recruitment of the Src-family kinase, Fyn, to these microdomains (Fig. 3A.)

The recruitment of Fyn to the microdomains upon receptor binding was consistent with a role for this kinase in communicating the signal downstream of ephrin-A5. In support of this hypothesis, the induction of tyrosine

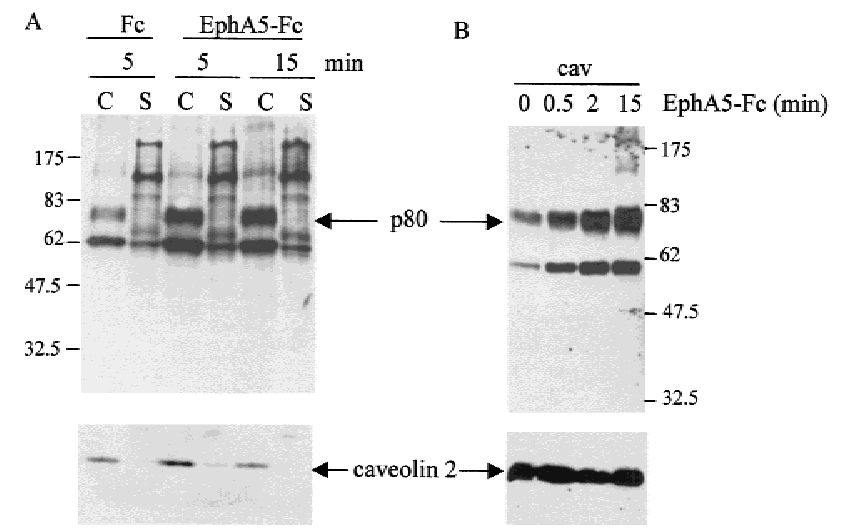

Figure 2. Ephrin-A5 is competent to transmit a compartmentalized signal event on binding to its cognate receptor. (A) NIH3T3 cells expressing ephrin-A5 were incubated for the times indicated with either Fc or EphA5-Fc. Cells were lysed and fractionated on a sucrose gradient. Both caveolae-like fractions (C) and soluble fractions (S) were analyzed by Western blot with the 4G10 antibody. The blot was reprobed with an anti-caveolin-2 antibody to control for the amount of TX-100 insoluble material loaded. $(B)$ Caveolae-like fractions purified from NIH3T3 cells expressing ephrin-A5 that were stimulated with EphA5-Fc for the times indicated (minutes) were analyzed by Western blotting with the 4G10 antibody. The blot was reprobed with anti-caveolin-2 antibody to control for the amount of material loaded. Molecular mass markers are indicated in $\mathrm{kD}$. 


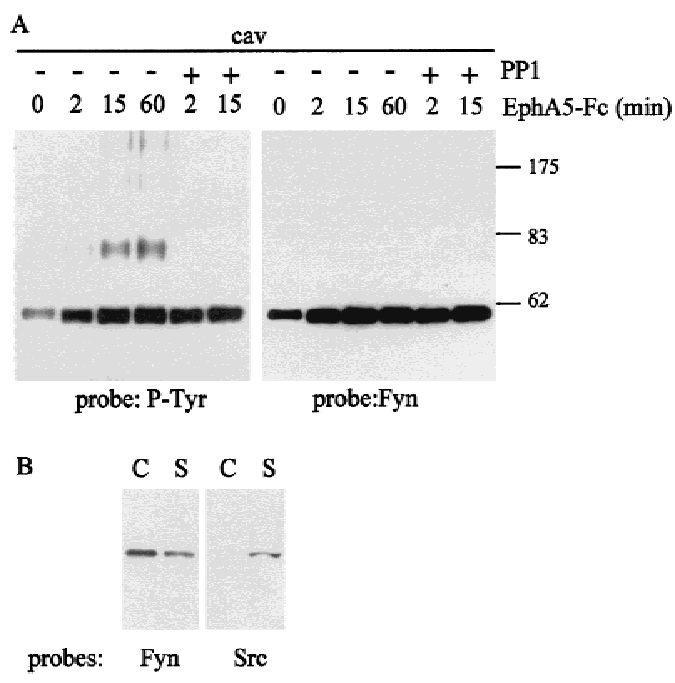

Figure 3. Fyn tyrosine kinase is recruited to the caveolae-like domains upon ephrin-A5 engagement. (A) NIH-3T3 cells expressing ephrin-A5 were incubated for different times with EphA5-Fc, in the absence or presence of PP1 as indicated. Caveolae-like fractions (cav) were isolated and analyzed by Western blot using in parallel 4G10 and an antibody specific for Fyn. (B) NIH-3T3 cells expressing ephrin-A5 were fractionated on a sucrose gradient. Caveolae-like fractions $(\mathrm{C})$ and soluble fractions (S) were tested by Western blot for the presence of Fyn and Src proteins. Molecular weight mass are indicated in $\mathrm{kD}$.

phosphorylation of the $\mathrm{p} 80$ phosphoprotein within the caveolae-like fraction was abrogated in the presence of $10 \mu \mathrm{M}$ PP1, a selective inhibitor for the Src-family kinases (Hanke et al. 1996) (Fig. 3A). Interestingly, PP1 treatment did not prevent the recruitment of Fyn to the microdomains, suggesting that the initial signaling event upstream of Fyn does not require the activity of the Src-family kinases (Fig. 3A).

Western bot analysis of fractionated NIH-3T3 cells demonstrated that unlike Fyn, Src itself was not associated with the caveolae-like fraction, although it could be detected in the detergent-soluble fraction (Fig. 3B). The differential localization of the Src-family kinases reflects the ability of Fyn to be modified by both myristoylation and palmitoylation (Alland et al. 1994) a necessary requirement for the association to the inner leaflet of caveolae-like domains (Robbins et al. 1995).

The identity of the heavily phosphorylated $\mathrm{p} 80$ protein is unknown but because its ability to be phosphorylated upon ephrin-A5 activation was abolished in the presence of PP1 (Fig. 3) it is possible that it is a substrate for the Src-family kinases. Consistent with this, we have shown that it binds to a glutathione fusion protein containing a prototype SH2 domain (GST Src-SH2) (Fig. 4) but not the Src-SH3 domain (data not shown), and its phoshorylation and/or binding was abrogated in the presence of PP1 (Fig. 4B). Based on Western blot analysis, it appears that $\mathrm{p} 80$ is not cortactin, paxillin, or the tyrosine phosphatase SHP-2 (data not shown).

\section{Analogous signaling competent microdomains exist in vivo in the CNS}

A signaling compartment, highly enriched for Fyn, caveolin, and a phosphoprotein consistent with p 80 was isolated from murine cortex (Fig. 5). Interestingly, the tyrosine phosphorylation levels of both Fyn and p80 were regulated during embryogenesis, with higher phosphorylation when brain remodeling occurs (E18) (Fig. $5 \mathrm{~A})$. Although we have not been able to definitively establish that ephrin-A5 is compartmentalized within these microdomains, we have determined that ephrinA5 is enriched within the caveolae-like domains of endogenously expressing cells including both the neuroblastoma cell line NG108-15 and primary human astrocytes and neurons (data not shown). It has also been observed independently that ephrin-A5 exhibits a patchlike appearance on primary neurons consistent with its presence in membrane microdomains (Hornberger et al. 1999).

To genetically confirm the direct role for Fyn in the compartmentalized signaling pathway, the caveolae-like fractions were isolated from the cortex of mice that were deficient for Fyn expression. Western blot analysis of the caveolae-like fractions isolated from the cortex of indi-

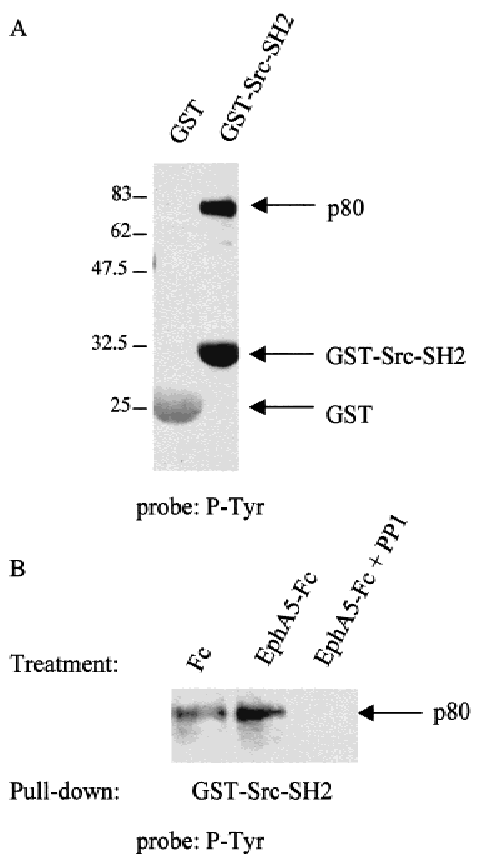

Figure 4. p80 is a putative substrate for Src-family kinases. (A) Caveolae-like fractions isolated from EphA5-Fc-stimulated fibroblasts were solubilized in TX-100 at $37^{\circ} \mathrm{C}$ for $30 \mathrm{~min}$ and incubated with $50 \mu \mathrm{g}$ of either purified GST or GST-Src-SH2 fusion proteins. Protein complexes were pelleted by low-speed centrifugation and analyzed by Western blotting using the phosphotyrosine-specific antibody 4G10. $(B)$ Caveolar fractions were isolated from ephrin-A5-expressing cells that had been treated with either Fc or EphA5-Fc in the presence or absence of PP1 (as indicated). Samples were analyzed as above with GST-Src-SH2 fusion protein and Western blotting with 4G10. Molecular mass markers are indicated $(\mathrm{kD})$. 


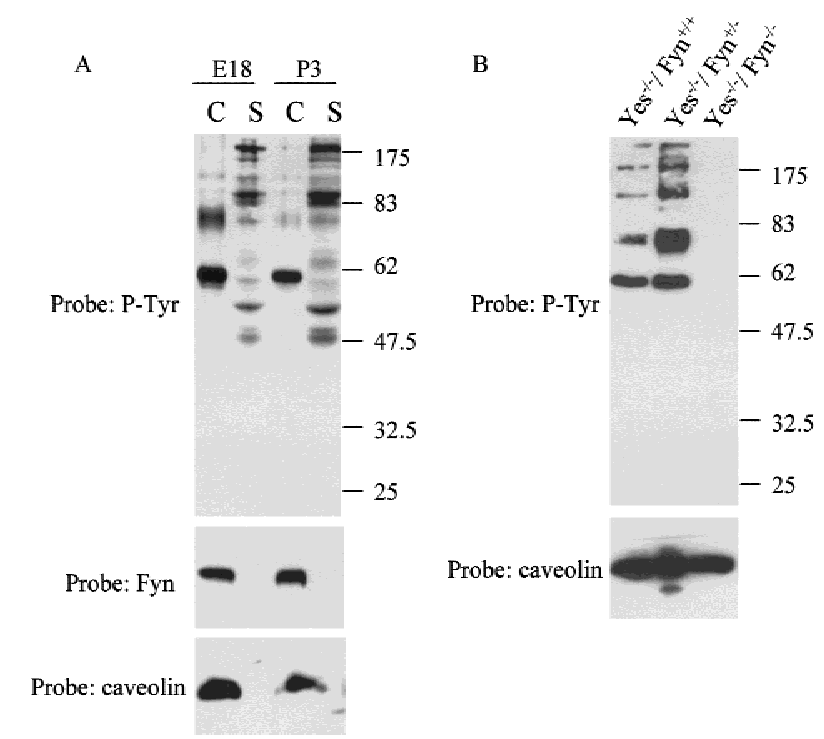

Figure 5. Fyn tyrosine kinase is essential for signaling in caveolae-like microdomains in vivo. (A) Caveolae-like microdomains $(\mathrm{C})$ and detergent soluble fractions $(\mathrm{S})$ were isolated from cortex of mice at different stages of development (E18 and P3). Samples were analyzed by Western blot using 4G10, caveolin-2, and Fyn-specific antibodies. (B) Caveolae-like fractions (cav) were isolated from brain of mice that were genotyped wild type $\left(\mathrm{Fyn}^{+/+}\right)$, defective for Fyn kinase $\left(\mathrm{Fyn}^{-/-}\right)$, or heterozygous $\left(\mathrm{Fyn}^{+/-}\right)$. Fractions were analyzed by Western blotting using 4G10 and an antibody specific for caveolin-2.

vidual embryos that were either wild-type $\left(\mathrm{Fyn}^{+/+}\right)$, heterozygous $\left(\mathrm{Fyn}^{+/-}\right)$, or homozygous $\left(\mathrm{Fyn}^{-/-}\right)$littermates demonstrated that the tyrosine phosphorylation events occurring in the microdomains in vivo are completely dependent on the presence of Fyn (Fig. 5B). Caveolin-2 was still detected in the $\mathrm{Fyn}^{-/-}$embryos, indicating that a similar amount of caveolae-like microdomains was present in these animals (Fig. 5B). It should be noted that the genetic analysis was done on animals that were also deficient in the expression of the Src-family kinase, Yes. The lack of only Yes expression (labeled Fyn ${ }^{+/+}$and Fyn ${ }^{+/} \mid$| was not sufficient to abrogate signaling within this compartment, but its contribution to the lack of compartmentalized signaling observed in the $\mathrm{Fyn}^{-/-}$animals remains to be determined as Yes would presumably also be present within the microdomains.

\section{Activation of ephrin-A5 induces changes in cellular architecture and adhesion}

During the course of establishing ephrin-A5 expressing cell lines, we observed that the growth rates of the cells were retarded significantly and that these cells were somewhat refractory to transformation by v-Src (A. Davy and S.M. Robbins, unpubl.). Furthermore, they displayed a different cellular morphology suggesting that ephrinA5 expression was not mitogenic but controls cytoskeletal architecture. This is consistent with the Eph recep- tor-mediated signaling that also appears to regulate cellular structure (Holland et al. 1997; Meima et al. 1997). To investigate whether ephrin-A5-induced signaling regulated cytoskeletal rearrangements and morphological changes, we examined cell attachment by staining focal adhesion complexes using vinculin as a marker. We found that binding of the EphA5-Fc receptor body to cells expressing ephrin-A5 caused a dramatic redistribution of the vinculin protein to focal adhesions that appeared more numerous and more intense (Fig. 6A). The regulation of cellular architecture was not limited to exogenously expressing cell systems as in primary cultures isolated from the inferior colliculus of day 3 postnatal mice, astrocytes (glial fibrillary acidic protein-positive cells) that endogenously express ephrin-A5 also exhibited dramatic changes in vinculin staining upon binding of EphA5-Fc (Fig. 6A, panels c and d). The changes in the various cell types were visible after $30 \mathrm{~min}$ in the presence of EphA5-Fc, and were reminiscent of those induced by the Rho family of GTPases (Rho, Rac, and Cdc42).

To assess the involvement of various protein kinases in this process, cells were incubated with PP1, a selective inhibitor for the Src-family kinases or with a relatively broad inhibitor of several of the protein kinase C (PKC) isozymes (Gö 6983) before exposure to EphA5-Fc. The number of focal adhesion complexes stained by the anti-vinculin antibody decreased when cells were treated with the kinase inhibitors (Fig. 6B, panels c-f), attesting that the drugs were active and probably affected the stability of focal adhesion complexes. In the presence of the PKC inhibitor, binding of EphA5-Fc to the cells still resulted in the redistribution of vinculin to focal adhesion complexes, suggesting that it is unlikely that the PKC enzymes are involved in mediating the structural changes observed (Fig. 6B, panels $\mathrm{c}$ and d). On the contrary, in presence of PP1, the binding of EphA5-Fc to ephrin-A5 did not induce any changes in the vinculin staining or in the number of focal adhesion complexes (Fig. 6B, panels e and f), suggesting that the Src-family of tyrosine kinases, presumably Fyn, is involved in the process leading to vinculin redistribution to focal adhesions. We were able to observe this biological effect as low as 3 $\mu \mathrm{m}$ PP1, which is well within the range for the in vivo specificity to the Src-family of protein tyrosine kinases (Hanke et al. 1996).

To further identify the physiological consequence induced by ephrin-A5 stimulation, we monitored the effect of the binding of EphA5-Fc on the adhesive properties of the cells. Fibroblasts expressing ephrin-A5 treated with EphA5-Fc demonstrated an increased adhesion to fibronectin as assessed by the number of cells adhering to the fibronectin-coated plates after extensive washing, as compared with cells treated with Fc (Fig. 7). In contrast, control cells transfected with the empty vector, that do not express ephrin-A5, were not significantly affected by the presence of EphA5-Fc in the medium (Fig. 7). More importantly, a similar increase in adhesive properties was also observed with the neuroblastoma cell line NG108-15, which endogenously expresses ephrin-A5 li- 
B

A
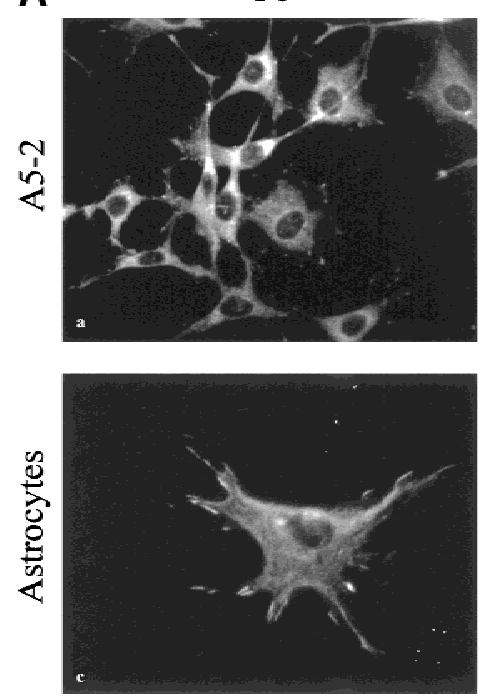
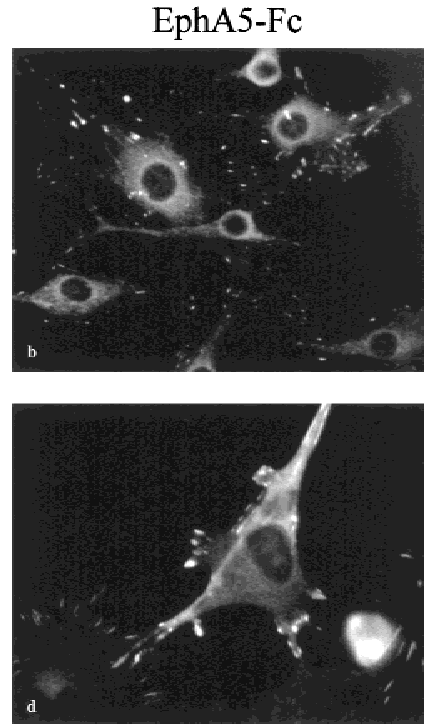

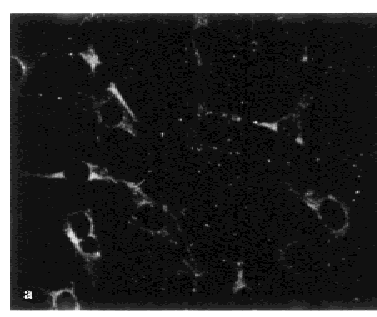

Fc
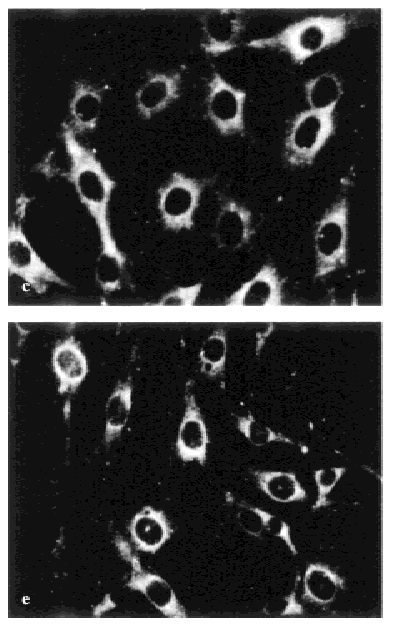

EphA5-Fc
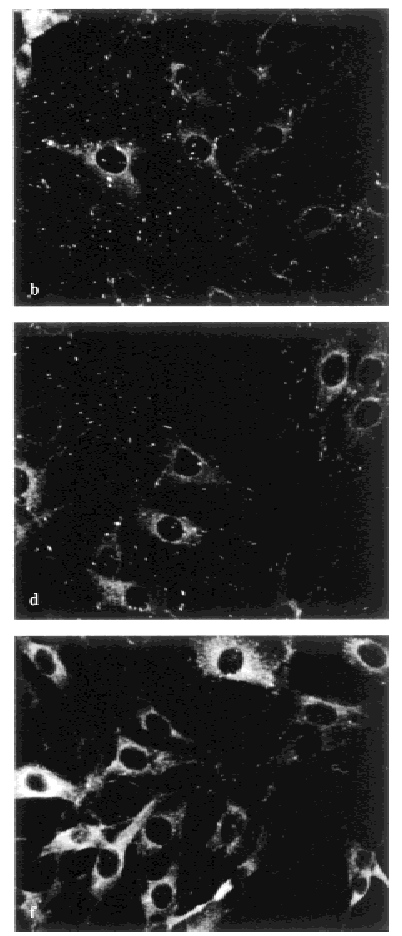

Figure 6. Binding of EphA5-Fc to ephrin-A5-expressing cells induces changes in cell architecture, requiring the Src-family kinases. (A) NIH-3T3 cells expressing ephrin-A5 (A5-2) $(a, b)$ and primary murine astrocytes $(c, d)$ were incubated with Fc $(a, c)$ or EphA5-Fc $(b, d)$ proteins for $30 \mathrm{~min}$ at $37^{\circ} \mathrm{C}$, fixed and subjected to indirect immunofluorescence using anti-vinculin monoclonal antibody (clone VIN-11-5, Sigma) and a $\mathrm{Cy}^{3}$-conjugated anti-mouse secondary antibody. (B) NIH-3T3 cells expressing ephrin-A5 (A5-2) (a-f) were incubated with Fc $(a, c, e)$ or EphA5-Fc $(b, d, f)$ proteins for $30 \mathrm{~min}$ at $37^{\circ} \mathrm{C}$, in the presence of either vehicle (DMSO) $(a, b), 1 \mu \mathrm{M}$ Gö 6983 $(c, d)$, or $10 \mu \mathrm{M}$ PP1 $(e, f)$. The cells were then fixed with methanol and subjected to indirect immunofluorescence using anti-vinculin monoclonal antibody.

gand (Fig. 7). When the cells were pretreated with PP1 (10 $\mu \mathrm{M})$, binding of EphA5-Fc did not induce an increased adhesion of the cells to fibronectin (data not shown)further evidence for a role of the Src-family kinases as effectors downstream of ephrin-A5. The interpretation of these results, however, remains difficult as pretreatment with PP1 affected the general adhesion properties of the cells.

\section{Discussion}

The work described in this report on GPI-anchored ephrin-A5 established that GPI-tethered ligands are involved in bidirectional signaling, as was described for transmembrane ephrins (Holland et al. 1996; Brückner et al. 1997). We have demonstrated that like other GPI-anchored proteins (Simons and Ikonen 1997; Anderson 1998), ephrin-A5 spontaneously localized within discrete plasma membrane microdomains that may equate to caveolae in some cell types. There is some controversy regarding the exact molecular nature of these membrane microdomains, but it is clear that they exist in cells and are enriched in various molecules involved in signal transduction (Simons and Ikonen 1997; Anderson 1998). There are at least two obvious consequences to the unique localization of ephrin-A5 within mem- brane microdomains. First, clustering of ephrin-A5 within the caveolae-like domains provides the level of oligomerization necessary for the efficient activation of its cognate Eph receptor (Davis et al. 1994; Stein et al. 1998). Second, compartmentalization localizes the GPIlinked ligand in the proximity of downstream effectors, thereby allowing the signal to be initiated. Interestingly, localization of ephrins-B and Eph receptors within caveolae-like domains has also been documented (Wu et al. 1997; Brückner et al. 1999).

The means by which GPI-anchored ephrin-A5 communicates with the intracellular milieu is not known, however, the most common mechanism underlying the ability of GPI-linked proteins to transmit a signal is by association with a transmembrane adapter protein. This type of mechanism has been described for various GPIlinked proteins, including GDNFR $\alpha$ or CNTFR (Davis and Yancopoulos 1993; Treanor et al. 1996). Another proposed mechanism for signal transduction through GPIlinked proteins involves enzymatic cleavage of the core protein by a specific phospholipase, resulting in the formation of a second messenger from the hydrolysis of the GPI moiety (Chan et al. 1989; Movahedi and Hooper 1997). That type of release would explain why ephrin-A5 can be purified in a soluble form in vivo (Lackmann et al. 1996, 1997). However, because we were unable to detect 


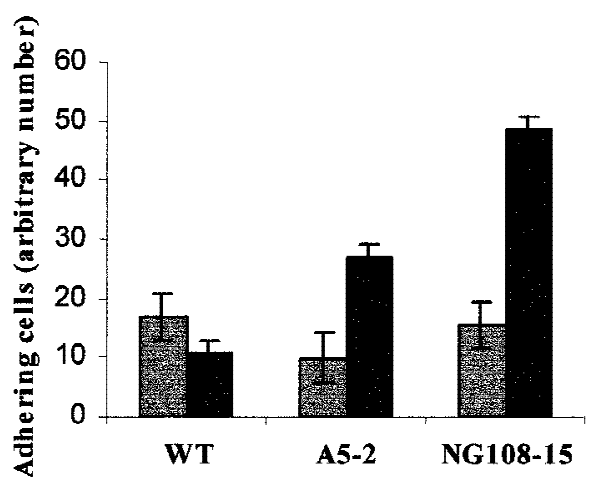

Figure 7. Activation of ephrin-A5 results in an increase in cellular adhesion. Cells expressing ephrin-A5 (A5-2 and NG10815) or cells transfected with the vector control (WT) were detached from their substratum by nonenzymatic removal, resuspended in low-serum containing media and spun down on plates coated with fibronectin. Cells were immediately incubated with either Fc (shaded bars) or EphA-Fc (solid bars) as indicated. Nonadhering cells were removed and the remaining adhering cells were trypsinized and counted. Values are expressed as the number of adhering cells from three different experiments (in triplicate).

a soluble form of the ligand in culture supernatants after binding of EphA5-Fc (data not shown), it is unlikely that a significant proportion of ephrin-A5 is cleaved upon engagement. This observation is in accordance with a published report stating that ephrin-A2 and ephrin-A5 are not detected in a supernatant media conditioned with posterior tectal membranes on which retinal axons were growing (Ichijo and Bonhoeffer 1998).

Src-family tyrosine kinases appear to be important regulators of signaling through GPI-linked proteins (Stefanova et al. 1991; Murray and Robbins 1998). Accordingly, we demonstrated that Src-related tyrosine kinase activity was essential for the signaling pathway downstream of ephrin-A5, because in the presence of the Src-family selective inhibitor, PP1 (Hanke et al. 1996), tyrosine phosphorylation of p80 induced upon engagement of ephrin-A5 was abrogated. We suspect Fyn to be the kinase responsible for the increased tyrosine phosphorylation of $\mathrm{p} 80$ based on its recruitment to the domains. Moreover, we showed that Src, unlike Fyn, was excluded completely from the microdomains. The differential localization of Src and Fyn in the microdomains reflects a difference in the fatty acid modifications of both proteins (Shenoy-Scaria et al. 1993; Alland et al. 1994; Robbins et al. 1995). Since fatty acid modification, particularly palmitoylation, governs the ability of Fyn to localize to caveolae-like domains, an interesting concept would be that the recruitment of Fyn to the microdomains in response of ephrin-A5 engagement is due to an increase in the palmitoylation levels on Fyn, achieved either by an increase in activity of a palmitoyl acyltransferase or inhibition of a palmitoyl thioesterase. Although there is currently little evidence for such a mechanism, it has been shown that there is rapid depalmitoylation of the Gs $\alpha$ subunit of the trimeric G-protein upon agonist stimulation (Wedgaertner and Bourne 1994).

The data presented in this work did not permit to establish whether Fyn became activated after its recruitment to the microdomains, or if already activated Fyn molecules were recruited to the domains. However, it is tempting to speculate that massive recruitment of a tyrosine kinase into a restricted environment could lead to a certain level of transactivation. This type of activation would be similar to what has been described for RTKs that are activated by dimerization. The slow kinetic of activation that is observed for both ephrin-A5 signaling and Eph receptors (Gale and Yancopoulos 1997) might impart a requirement for high complexity clusters of protein kinases to form before maximal activation is achieved. One of the major consequences of the activation of Fyn within the caveolae-like domains was the tyrosine phosphorylation of $\mathrm{p} 80$. From the results presented, we cannot definitively rule out that the apparent increase in tyrosine phosphorylation of $\mathrm{p} 80$ in response to ephrin-A5 engagement is due to the recruitment of $\mathrm{p} 80$ to the domains. The fact that PP1 blocked the tyrosine phosphorylation of p 80 without blocking Fyn recruitment, however, indicates that translocation is unlikely to account for the increased tyrosine phosphorylation because translocation events occurred normally in presence of PP1 and yet tyrosine phosphorylation of $\mathrm{p} 80$ was abrogated. To definitively establish the role of Fyn in the compartmentalized signaling, we showed that this particular member of the Src family of tyrosine kinases is highly enriched in caveolae-like domains isolated from cortex, and that its level of tyrosine phosphorylation correlated with that of $\mathrm{p} 80$. Analysis of mice deficient for Fyn revealed that tyrosine phosphorylation within the caveolae-like domains was completely abrogated in the absence of this kinase. The differential tyrosine phosphorylation of $\mathrm{p} 80$ in the caveolae-like domains of embryos between E18 and P3 indicated a temporal regulation of the compartmentalized signaling and a possible functional involvement of the microdomains in the nervous system development. Interestingly, tyrosine phosphorylation of $\mathrm{p} 80$ was diminished at $\mathrm{P} 3$, a time when guidance and migration processes are no longer prevalent because most of the axons have reached their target structure. In addition, mice deficient for Fyn exhibit defects in axon guidance (Morse et al. 1998). Although our genetic data are consistent with a role for Fyn downstream of ephrin-A5 signaling, the caveolae-like domains may not be exclusive for ephrin-A5 and more likely represent sites of compartmentalized signaling for a number of different extracellular signals.

In accordance with a role for ephrin-A5 in axon guidance and migration, we demonstrated that the signaling induced by ephrin-A5 engagement resulted in a change in the adhesive properties of the cells. Unexpectedly, however, we observed an increased adhesion of the cells to fibronectin following ephrin-A5 engagement, in contradiction with the repulsion process that has been reported previously (Drescher et al. 1995; Winslow et al. 1995). In support of the result obtained with cells ecto- 
pically expressing ephrin-A5, we also observed a similar increased adhesion with cells endogenously expressing ephrin-A5. We attempted to evaluate the involvement of members of the Src family of tyrosine kinases in this process, by pretreating the cells with PP1 before engagement of ephrin-A5. The interpretation of these results, however, was hampered by the fact that the drug dramatically affected the ability of the cells to adhere to fibronectin, independently of the treatment applied (data not shown). This is consistent with the direct role that the Src-family kinases have in integrin-mediated adhesion (Lowell et al. 1996; Meng and Lowell 1998; Klinghoffer et al. 1999).

We were able to correlate the compartmentalized signaling induced upon engagement of ephrin-A5 with the regulation of cell adhesion and morphology by monitoring later events such as the cellular distribution of vinculin, which is a protein participating in the formation of focal adhesion complexes. We observed that upon ephrin-A5 engagement, vinculin protein redistributed to focal adhesions, in a time frame and a fashion similar to that following activation of Rac or Cdc42 (Ridley and Hall 1992; Nobes and Hall 1994). Importantly, the process of redistribution was not restricted to fibroblasts, but also occurred in primary astrocytes upon engage-

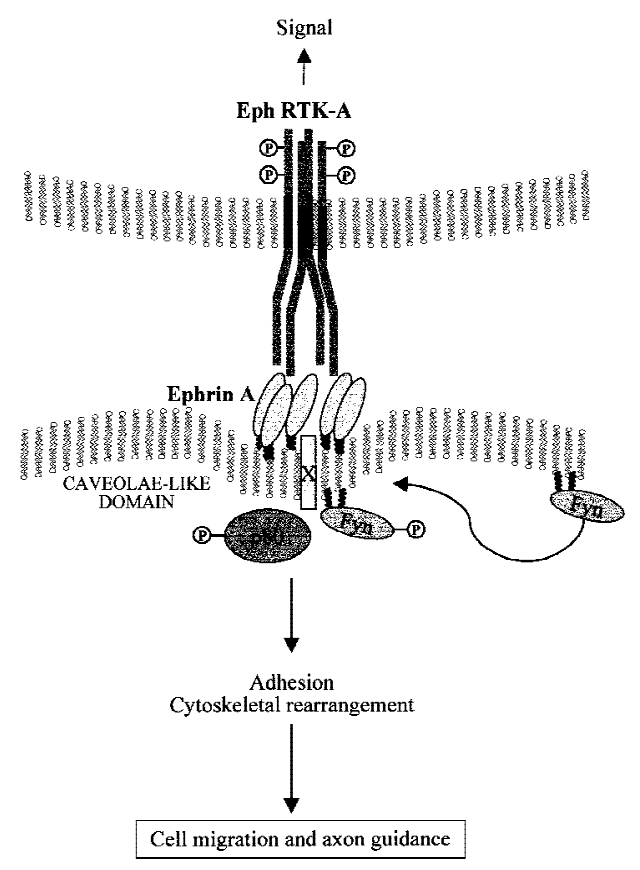

Figure 8. Model for the activation of ephrin-A ligands regulating cellular architecture. Ephrin-A5 is localized to discrete membrane microdomains. Upon binding to its cognate Eph receptor expressed on a neighboring cell, a signal is initiated within the ephrin-A5-expressing cell. This signal, presumably requiring the Rho family of small molecular weight GTPases, results in a change in cellular adhesion that may affect neuronal migration and guidance. The unknown p 80 phosphoprotein, the Src-family kinase Fyn, and a putative transmembrane adapter protein $(\mathrm{X})$ are indicated and presumably perform some essential functions during intracellular signaling. ment of ephrin-A5. To convincingly correlate the phenomenon affecting vinculin protein to the signaling through ephrin-A5, we demonstrated that the redistribution of vinculin to focal adhesions following ephrin-A5 engagement was strictly dependent on the activity of a Src-family kinase. In the presence of PP1, ephrin-A5 stimulation did not result in the redistribution of vinculin, correlating with the absence of signaling in the microdomains and absence of tyrosine phosphorylation of p80. On the contrary, treatment with a PKC inhibitor did not affect ephrin-A5-induced redistribution of vinculin.

A proposed model for the role of ephrins in controlling cellular architecture and adhesion is depicted in Figure 8. Upon binding of the extracellular domain of the Eph receptor to the ephrin-A ligands, a bidirectional signal is initiated in both receptor and ligand expressing cells. The ephrin-A molecule transduces the signal across the plasma membrane by association with a proposed transmembrane adaptor $(\mathrm{X})$. The signaling event results in the recruitment and activation of Fyn within the caveolaelike domains and the subsequent tyrosine phosphorylation of $\mathrm{p} 80$. The physiological consequences of ephrinA5 engagement reveal a complex role for the ephrins in activating as well as modulating Eph receptor signaling, in accordance with a recent report (Hornberger et al. 1999). This study, involving a signaling-competent ephrin-A ligand linked to the regulation of cellular morphology, provides evidence for compartmentalized signaling being instrumental during brain development.

\section{Materials and methods}

Reagents

The EphA5-Fc receptor bodies and control Fc were prepared as described previously (Davis et al. 1994; Gale et al. 1996). A monoclonal antibody (5G2) was generated using a glutathione fusion protein encompassing amino acids 15-126 of ephrin-A5 as an antigen. The antibodies used in this study are as follows: anti-phosphotyrosine monoclonal 4G10 (Upstate Biotechnology, Inc.), monoclonal antibody raised against chicken vinculin (Clone VIN-11-5, Sigma), monoclonal antibodies to Src and Fyn were from Upstate Biotechnology, Inc. and Transduction Laboratories, respectively, and both caveolin-1 and caveolin-2 monoclonal antibodies were from Transduction Laboratories.

\section{Establishment of ephrin-A5-expressing cell lines}

NIH-3T3 cells were transfected with $10 \mu \mathrm{g}$ of ephrin-A5 expression vector and either $1 \mu \mathrm{g}$ of LNCX vector or $1 \mu \mathrm{g}$ of pBabepuro using calcium phosphate precipitation (Canadian Life Technologies, GIBCO); individual clones were selected using 600 $\mu \mathrm{g} / \mathrm{ml} \mathrm{G418}$ or $2 \mu \mathrm{g} / \mathrm{ml}$ puromycin, respectively. Resistant clones were screened for ephrin-A5 expression by indirect immunofluorescence. Briefly, cells were incubated for $20 \mathrm{~min}$ in PBS containing $1 \mathrm{\mu g} / \mathrm{ml}$ EphA5-Fc chimera at room temperature and washed twice in media. Bound chimera was then detected by anti-human Fc-specific antibodies conjugated with FITC and cells were analyzed by FACScan. All cell lines were maintained in Dulbecco's Modified Eagle Medium (DMEM) supplemented with $10 \%$ fetal calf serum (FCS; Canadian Life Technologies, GIBCO). 


\section{Primary cultures}

Inferior colliculus from postnatal day 3 (P3) mouse pups was dissociated, and the cells were plated on polyornithine-coated coverslips and grown in DMEM supplemented with 10\% FCS.

\section{Immunofluorescence microscopy}

For experiments using kinase inhibitors, cells were preincubated with either $1 \mu \mathrm{M}$ Gö 6983 (Calbiochem), a pharmacological inhibitor of several PKC isozymes (Gschwëndt et al. 1996), or with $1-10 \mu \mathrm{M} P P 1$ for $30 \mathrm{~min}$ at $37^{\circ} \mathrm{C}$. The incubation with Fc or EphA5-Fc was performed in the continued presence of the inhibitors. For caveolin staining, cells were fixed for $10 \mathrm{~min}$ in $100 \%$ methanol at $-20^{\circ} \mathrm{C}$, washed in PBS and incubated for $1 \mathrm{hr}$ at room temperature in PBS/1\% BSA containing a caveolin-1specific monoclonal antibody $(2.5 \mu \mathrm{g} / \mathrm{ml})$. After extensive washing in PBS, cells were incubated with a goat anti-mouse secondary antibody conjugated to Cy3 for $1 \mathrm{hr}$ followed by washing. For indirect staining of the ligand using the EphA5-Fc chimera, viable cells were incubated in PBS containing $8 \mu \mathrm{g} / \mathrm{ml}$ EphA5$\mathrm{Fc}$ for $15 \mathrm{~min}$ at $37^{\circ} \mathrm{C}$. Binding of the secondary antibody (antiFc fragment of human IgG conjugated with FITC) was done as described above. For functional assays, cells were plated on fibronectin (NIH-3T3 clones) or polyornithine (primary cultures)coated coverslips. Cells were serum starved for $3 \mathrm{hr}$ and were then incubated with either Fc (control) or EphA5-Fc for $30 \mathrm{~min}$ at $37^{\circ} \mathrm{C}$, quickly rinsed in $\mathrm{PBS}$, and subjected to methanol fixation. Immunofluorescence was then performed with the vinculin monoclonal antibody (1:100 dilution of ascites) as described for caveolin (see above).

\section{Adhesion assay}

NG108-15 cells and fibroblasts stably transfected with either ephrin-A5 cDNA or with the vector control were detached from the tissue culture plates by using PUCKS-EDTA $15 \mathrm{~mm} \mathrm{KCl}$, $130 \mathrm{~mm} \mathrm{NaCl}, 3 \mathrm{~mm} \mathrm{NaHCO}$, 5 mM D-glucose, $10 \mathrm{~mm}$ HEPES at $\mathrm{pH} 7.3,1 \mathrm{~mm}$ EDTA) to preserve the integrity of the extracellular proteins. Cells were resuspended in DMEM containing $0.5 \%$ cosmic calf serum and incubated for $30 \mathrm{~min}$ at $37^{\circ} \mathrm{C}$. One milliliter of cell suspension $\left(0.25 \times 10^{6}\right.$ cells $\left./ \mathrm{ml}\right)$ was plated per well precoated with fibronectin and the plates were immediately spun at $800 \mathrm{rpm}$ for $3 \mathrm{~min}$. The medium was then supplemented with $8 \mu \mathrm{g} / \mathrm{ml}$ of either Fc or EphA5-Fc. After 5 min at $37^{\circ} \mathrm{C}$ for fibroblasts (30 min for NG108-15), the nonadhering cells were removed by extensive, aggresive washing with PBS. The remaining adhering cells were then trypsinized and counted in a hemocytometer. The data are accumulated from three independent experiments performed in triplicate and are displayed as the number of adhering cells.

\section{Cell stimulations and biochemical purification of DIGs}

Confluent monolayers of cells (150-mm plates) were incubated with either $2 \mu \mathrm{g} / \mathrm{ml} \mathrm{Fc}$, or $2 \mu \mathrm{g} / \mathrm{ml}$ EphA5-Fc in DMEM media containing $10 \%$ cosmic calf serum (HyClone) for the indicated times. The DIGs were then purified as described in detail previously (Robbins et al. 1995). For the pull-down experiments, the caveolar fraction was harvested and solubilized by incubation at $37^{\circ} \mathrm{C}$ in the presence of $1 \%$ Triton $\mathrm{X}-100$. The solubilized caveolar fraction was then incubated with either purified GST fusion proteins, Fc or EphA5-Fc at $4^{\circ} \mathrm{C}$ for $2 \mathrm{hr}$, and the protein complexes were purified by the addition of either glutathione-agarose or protein A-Sepharose, respectively. The pro- tein complexes were then pelleted by low-speed centrifugation and washed several times in PBS. All samples were analyzed by Western blotting after transfer to nitrocellulose membranes as described previously (Robbins et al. 1995) using enhanced chemiluminescence detection reagents (Amersham). For the purification of the DIG fraction from brain tissues, the cortex was isolated from stage E18 and P3 mice and solubilized in Triton $\mathrm{X}$-100 lysis buffer using a dounce homogenizer. A low-speed (3000 rpm) clearing spin was performed to remove insoluble debris and the cleared lysates were adjusted to a final concentartion of $40 \%$ sucrose and overlayed with a linear sucrose gradient as described previously (Robbins et al. 1995). Embryos were also collected at E16.5 from $\mathrm{Src}^{+/-} \mathrm{Yes}^{-/-} \mathrm{Fyn}^{+/-}$parents. Hybrid (129Sv:C57 B1/6) animals were used for these crosses. PCR was used to genotype embryos for the Src and Fyn loci. PCR for Src was performed as described previously (Thomas et al. 1995). For the Fyn locus, a forward primer from intron 2 $\left(5^{\prime}\right.$-GTCCСТCTTCCCACTCTTC-3') and a reverse primer from intron 2 (5'-TACTCCCAACGCTCACTAA-3') were used to amplify a 270-bp fragment from the wild-type allele. The forward primer and a neo ${ }^{r}$-specific reverse primer $\left(5^{\prime}\right.$ CGCCTTCTATCGCCTTCTT-3') amplify a 450-bp fragment from the mutant allele. The cortex was removed from the genotyped embryos and the DIG fraction was isolated as described above.

\section{Acknowledgments}

We express our gratitude to Drs. V. Wee Yong and Brian Burke for their assistance with the immunofluorescence experiments. We also thank Drs. Julie Deans, Wee Yong, and Brian Burke for their critical comments on this manuscript. We acknowledge members of the Regeneron community, including the protein sciences group, for their generosity in producing the Fc fusion proteins used in this study, and particularly Dr. George D. Yancopoulos for his insightful support. A.D. has received partial funding support from a Government of Canada Award and from a Eurodoc Fellowship; E.W.M. is supported by postdoctoral fellowships from the Medical Research Council of Canada and the Alberta Heritage Foundation for Medical Research (AHFMR); and R.A.K. is supported by a National Institutes of Health (NIH) postdoctoral fellowship (HD08412). S.M.R. is an AHFMR scholar. This work was supported by grants from the Medical Research Council of Canada to S.M.R. and from the NIH to P.S.

The publication costs of this article were defrayed in part by payment of page charges. This article must therefore be hereby marked "advertisement" in accordance with 18 USC section 1734 solely to indicate this fact.

\section{References}

Alland, L., S.M. Peseckis, R.E. Atherton, L. Berthiaume, and M.D. Resh. 1994. Dual myristylation and palmitylation of Src family member p59fyn affects subcellular localization. $J$. Biol. Chem. 269: 16701-16705.

Anderson, R.G.W. 1993. Plasmalemmal caveolae and GPI-anchored membrane proteins. Curr. Opin. Cell Biol. 5: 647652.

- 1998. The caveolae membrane system. Annu. Rev. Biochem. 67: 199-225.

Brown, D. 1993. The tyrosine kinase connection: How GPIanchored proteins activate $\mathrm{T}$ cells. Curr. Opin. Immunol. 5: 349-354. 
Brown, D.A. and J.K. Rose. 1992. Sorting of GPI-anchored proteins to glycolipid-enriched membrane subdomains during transport to the apical cell surface. Cell 68: 533-544.

Brückner, K., E.B. Pasquale, and R. Klein. 1997. Tyrosine phosphorylation of transmembrane ligands for Eph receptors. Science 275: 1640-1643.

Brückner, K., J.P. Labrador, P. Scheiffele, A. Herb, P.H. Seeburg, and R. Klein. 1999. EphrinB ligands recruit GRIP family PDZ adaptor proteins into raft membrane microdomains. Neuron 22: $511-524$.

Cameron, P.L., J.W. Ruffin, R. Boolag, H. Rasmussen, and R.S. Cameron. 1997. Identification of caveolin and caveolin-related proteins in the brain. J. Neurosci. 17: 9520-9535.

Caras, I.W. 1997. A link between axon guidance and axon fasciculation suggested by studies of the tyrosine kinase receptor EphA5/REK7 and its ligand Ephrin-A5/AL1. Cell Tissue Res. 290: 261-264.

Chan, B.L., M.V. Chao, and A.R. Saltiel. 1989. Nerve growth factor stimulates the hydrolysis of glycosyl-phosphatidylinositol in PC-12 cells: A mechanism of protein kinase C regulation. Proc. Natl. Acad. Sci. 86: 1756-1760.

Chang, W.J., Y.S. Ying, K.G. Rothberg, N.M. Hooper, A.J. Turner, H.A. Gambliel, J. De Gunzburg, S.M. Mumby, A.G. Gilman, and R.G. Anderson. 1994. Purification and characterization of smooth muscle cell caveolae. I. Cell Biol. 126: $127-138$.

Davis, S., N.W. Gale, T. Aldrich, P.C. Maisonpierre, V. Lhotak, T. Pawson, M. Goldfarb, and G.D. Yancopoulos. 1994. Ligands for Eph-related receptor tyrosine kinases that require membrane attachment or clustering for activity. Science 266: 816-819.

Davis, S. and G.D. Yancopoulos. 1993. The molecular biology of the CNTF receptor. Curr. Opin. Cell Biol. 5: 281-285.

Drescher, U., C. Kremoser, C. Handwerker, J. Loschinger, M. Noda, and F. Bonhoeffer. 1995. In vitro guidance of retinal ganglion cell axons by RAGS, a $25 \mathrm{kDa}$ tectal protein related to ligands for Eph receptor tyrosine kinases. Cell 82: 359370.

Drescher, U., F. Bonhoeffer, and B.K. Muller. 1997. The Eph family in retinal axon guidance. Curr. Opin. Neurobiol. 7: 75-80.

Friedman, G.C. and D.D.M. O'Leary. 1996. Eph receptor tyrosine kinases and their ligands in neural development. Curr. Opin. Neurobiol. 6: 127-133.

Frisén, J. and M. Barbacid. 1997. Genetic analysis of the role of Eph receptors in the development of the mammalian nervous system. Cell Tissue Res. 290: 209-215.

Frisén, J., P.A. Yates, T. McLaughlin, G.C. Friedman, D.D.M O'Leary, and M. Barbacid. 1998. Ephrin-A5 (AL-1/RAGS) is essential for proper retinal axon guidance and topographic mapping in the mammalian visual system. Neuron 20: 235 243.

Gale, N.W. and G.D. Yancopoulos. 1997. Ephrins and their receptors: A repulsive topic? Cell Tissue Res. 290: 227-241.

Gale, N.W., S.J. Holland, D.M. Valenzuela, A. Flenniken, L. Pan, T.E. Ryan, M. Henkemeyer, K. Strebhardt, H. Hirai, D.G. Wilkinson et al. 1996. Eph receptors and ligands comprise two major specificity subclasses, and are reciprocally compartmentalized during embryogenesis. Neuron 17: 9-19.

Gao, P.-P., Y. Yue, J.-H. Zhang, D.P. Cerreti, P. Levitt, and R. Zhou. 1998. Regulation of thalamic neurite outgrowth by the Eph ligand ephrin-A5: Implication in the development of thalamocortical projections. Proc. Nat1. Acad. Sci. 95: 53295334.

Gschwëndt, M., S. Dieterich, J. Rennecke, W. Kittstein, H.J. Mueller, and F.J. Johannes. 1996. Inhibition of protein kinase
$\mathrm{C}$ mu by various inhibitors. Differentiation from protein kinase C isozymes. FEBS Lett. 392: 77-80.

Hanke, J.H., J.P. Gardner, R.L. Dow, P.S. Changelian, W.H. Brissette, E.J. Weringer, B.A. Pollok, and P.A. Connelly. 1996 Discovery of a novel, potent, and src family-selective tyrosine kinase inhibitor. J. Biol. Chem. 271: 695-701.

Harder, T. and K. Simons. 1997. Caveolae, DIGS, and the dynamics of sphingolipid-cholesterol microdomains. Curr. Opin. Cell Biol. 9: 534-542.

Henkemeyer, M., D. Orioli, J.T. Henderson, T.M. Saxton, J. Roder, T. Pawson, and R. Klein. 1996. Nuk controls pathfinding of commissural axons in the mammalian central nervous system. Cell 86: 35-46.

Holland, S.J., N.W. Gale, G.D. Gish, R.A. Roth, Z. Songyang, L.C. Cantley, M. Henkemeyer, G.D. Yancopoulos, and T. Pawson. 1997. Juxtamembrane tyrosine residues couple the Eph family receptor EphB2/Nuk to specific SH2 domain proteins in neuronal cells. EMBO I. 16: 3877-3888.

Holland, S.J., N.W. Gale, G. Mbamalu, G.D. Yancopoulos, M. Henkemeyer, and T. Pawson. 1996. Bidirectional signalling through the EPH-family receptor Nuk and its transmembrane ligands. Nature 383: 722-725.

Hornberger, M.R., D. Dutting, T. Ciossek, T. Yamada, C. Handwerker, S. Lang, F. Weth, J. Huf, R. Wessel, C. Logan et al 1999. Modulation of EphA receptor function by coexpressed ligands on retinal ganglion cell axons. Neuron 22: 731-742.

Ichijo, H. and F. Bonhoeffer. 1998. Differential withdrawal of retinal axons induced by a secreted factor. J. Neurosci. 18: $5008-5018$.

Ikezu, T., H. Ueda, B.D. Trapp, K. Nishiyama, J.F. Sha, D. Volonte, F. Galbiati, A.L. Byrd, G. Bassell, H. Serizawa et al. 1998. Affinity-purification and characterization of caveolins from the brain: Differential expression of caveolin-1, -2, -3 in brain endothelial and astroglial cell types. Brain Res. 804: 177-192

Klinghoffer, R.A., C. Sachsenmaier, J.A. Cooper, and P. Soriano, 1999. Src family kinases are required for integrin but not PDGFR signal transduction. EMBO J. 18: 2459-2471.

Lackmann, M., T. Bucci, R.J. Mann, L.A. Kravets, E. Viney, F. Smith, R.L. Moritz, W. Carter, R.J. Simpson, N.A. Nicola et al. 1996. Purification of a ligand for the EPH-like receptor HEK using a biosensor-based affinity detection approach. Proc. Natl. Acad. Sci. 93: 2523-2527.

Lackmann, M., R.J. Mann, L. Kravets, F.M. Smith, T.A. Bucci, K.F. Maxwell, G.J. Howlett, J.E. Olsson, T. Vanden Bos, D.P. Cerreti et al.. 1997. Ligand for EPH-related kinase (LERK) 7 is the preferred high affinity ligand for the HEK receptor. $J$. Biol. Chem. 272: 16521-16530.

Lisanti, M.P., P.E. Scherer, J. Vidugiriene, Z. Tang, A. Hermanowski-Vosatka, Y.H. Tu, R.F. Cook, and M. Sargiacomo. 1994. Characterization of caveolin-rich membrane domains isolated from an endothelial-rich source: Implications for human disease. J. Cell Biol. 126: 111-126.

Lowell, C.A., L. Fumagalli, and G. Berton. 1996. Deficiency of Src family kinases p59/61hck and p58c-fgr results in defective adhesion-dependent neutrophil functions. I. Cell Biol. 133: 895-910.

Meima, L., I.J. Klavin, P. Moran, A. Shih, J.W. Winslow, and I.W. Caras. 1997. AL-1-induced growth cone collapse of rat cortical neurons is correlated with REK7 expression and rearrangement of the actin cytoskeleton. Eur. I. Neurosci. 9: $177-188$.

Meng, F. and C.A. Lowell. 1998. A beta 1 integrin signaling pathway involving Src-family kinases, $\mathrm{Cbl}$ and PI-3 kinase is required for macrophage spreading and migration. EMBO $J$. 17: 4391-4403. 
Monier, S., R. Parton, F. Vogel, J. Behlke, A. Henske, and T. Kurzchalia. 1995. VIP21-caveolin, a membrane protein constituent of the caveolar coat, oligomerizes in vivo and in vitro. Mol. Biol. Cell 6: 911-927.

Morse, W.R., J.G. Whitesides, A.S. LaMantia, and P.F. Maness. 1998. p59fyn and pp60c-src modulate axonal guidance in the developing mouse olfactory pathway. J. Neurosci. 36: 53-63.

Movahedi, S. and N.M. Hooper. 1997. Insulin stimulates the release of glycosyl phosphatidylinositol-anchored membrane dipeptidase from 3T3-L1 adipocytes through the action of a phospholipase C. Biochem. J. 326: 531-537.

Murray, E.W. and S.M. Robbins. 1998. Antibody cross-linking of the glycosylphosphatidylinositol-linked protein CD59 on hematopoietic cells induces signaling pathways resembling activation by complement. J. Biol. Chem. 273: 25279-25284.

Nobes, C. and A. Hall. 1994. Regulation and function of the Rho subfamily of small GTPases. Curr. Opin. Gen. Dev. 4: 77-81.

Ridley, A.J. and A. Hall. 1992. The small GTP-binding protein rho regulates the assembly of focal adhesions and actin stress fibers in response to growth factors. Cell 70: 389-399.

Robbins, S.M., N.A. Quintrell, and J.M. Bishop. 1995. Myristoylation and differential palmitoylation of the HCK protein-kinases govern their attachment to membranes and association with caveolae. Mol. Cell. Biol. 15: 3507-3515.

Rothberg, K.G., J.E. Heuser, W.C. Donzell, Y.-S. Ying, J.R. Glenney, and R.G.W. Anderson. 1992. Caveolin, a protein component of caveolae membrane coats. Cell 68: 673-682.

Sargiacomo, M., M. Sudol, Z. Tang, and M.P. Lisanti. 1993. Signal transducing molecules and glycosyl-phosphatidylinositol-linked proteins form a caveolin-rich insoluble complex in MDCK cells. J. Cell Biol. 122: 789-809.

Scherer, P.E., T. Okamoto, M. Chun, I. Nishimoto, H.F. Lodish, and M.P. Lisanti. 1996. Identification, sequence and expression of caveolin-2 defines a caveolin gene family. Proc. Nat1. Acad. Sci. 93: 131-135.

Shenoy-Scaria, A.M., L.K. Timson Gauen, J. Kwong, A.S. Shaw, and D.M. Lublin. 1993. Palmitylation of an amino-terminal cysteine motif of protein tyrosine kinases p56lck and p59fyn mediates interaction with glycosyl-phosphatidylinositol-anchored protein. Mol. Cell. Biol. 13: 6385-6392.

Shenoy-Scaria, A.M., D.J. Dietzen, J. Kwong, D.C. Link, and D.M. Lublin. 1994. Cysteine (3) of Src family protein tyrosine kinases determines palmitoylation and localization in caveolae. J. Cell. Biol. 126: 353-363.

Simons, K. and E. Ikonen. 1997. Functional rafts in cell membranes. Nature 387: 569-572.

Stefanova, I., V. Horejsi, I.J. Ansotegui, W. Knapp, and H. Stockinger. 1991. GPI-anchored cell surface molecules complexed to protein tyrosine kinases. Science 254: 1016-1019.

Stein, E., A.A. Lane, D.P. Cerreti, H.O. Schoecklmann, A.D. Schroff, R.L. Van Etten, and T.O. Daniel. 1998. Eph receptors discriminate specific ligand oligomers to determine alternative signaling complexes, attachment, and assembly responses. Genes \& Dev. 12: 667-678.

Tang, Z., P.E. Scherer, T. Okamoto, K. Song, C. Chu, D.S. Kohtz, I. Nishimoto, H.F. Lodish, and M.P. Lisanti. 1996. Molecular cloning of caveolin-3, a novel member of the caveolin gene family expressed predominantly in muscle. $I$. Biol. Chem. 268: 9-12.

Thomas, S.M., P. Soriano, and A. Imamoto. 1995. Specific and redundant roles of Src and Fyn in organizing the cytoskeleton. Nature 376: 267-271.

Treanor, J.J., L. Goodman, F. de Sauvage, D.M. Stone, K.T. Poulsen, C.D. Beck, C. Gray, M.P. Armanini, R.A. Pollock, F. Hefti et al. 1996. Characterization of a multicomponent receptor for GDNF. Nature 382: 80-83.
Way, M. and R.G. Parton. 1995. M-caveolin, a muscle specific caveolin-related protein. FEBS Lett. 376: 108-112.

Wedgaertner, P.B. and H.R. Bourne. 1994. Activation and depalmitoylation of Gs alpha. Cell 77: 1063-1070.

Winslow, J.W., P. Moran, J. Valverde, A. Shih, J.Q. Yuan, S.C. Wong, S.P. Tsai, A. Goddard, W.J. Henzel, F. Hefti et al. 1995. Cloning of AL-1, a ligand for an Eph-related tyrosine kinase receptor involved in axon bundle formation. Neuron 14: 973-981.

Wu, C., S. Butz, Y. Ying, and R.G.W. Anderson. 1997. Tyrosine kinase receptors in caveolae-like domains from neuronal plasma membrane. J. Biol. Chem. 272: 3554-3559.

Yancopoulos, G.D., M. Klagsbrun, and J. Folkman. 1998. Vasculogenesis, angiogenesis, and growth factors: Ephrins enter the fray at the border. Cell 93: 661-664. 


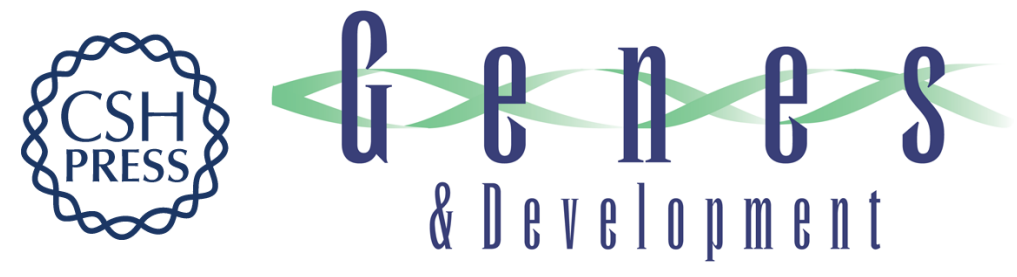

\section{Compartmentalized signaling by GPI-anchored ephrin-A5 requires the Fyn tyrosine kinase to regulate cellular adhesion}

Alice Davy, Nicholas W. Gale, Elizabeth W. Murray, et al.

Genes Dev. 1999, 13:

References This article cites 58 articles, 27 of which can be accessed free at:

http://genesdev.cshlp.org/content/13/23/3125.full.html\#ref-list-1

License

Email Alerting

Service right corner of the article or click here.

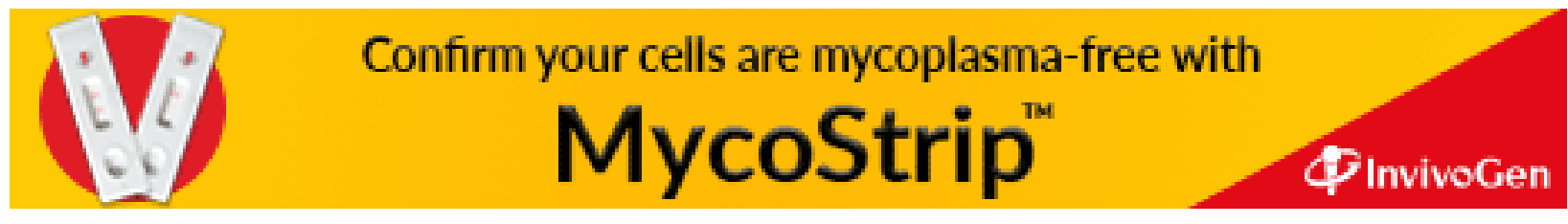

